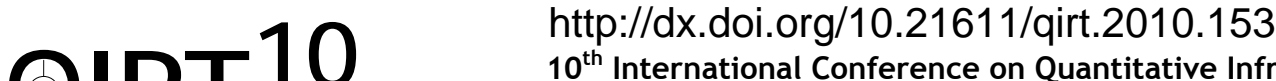 \\ $10^{\text {th }}$ International Conference on Quantitative InfraRed Thermography \\ July 27-30, 2010, Québec (Canada)
}

\section{Quantitative method of evaluating for recognize people, based on thermograms}

\author{
by G. Owczarek*, R. Strąkowski** and M. Więcek** \\ ${ }^{*}$ Central Institute for Labour Protection - National Research Institute, Warsaw and Lodz, Poland, \\ growc@ciop.lodz.pl \\ **Technical University of Lodz, Lodz, Poland, acidprv@gmail.com
}

\begin{abstract}
This article present quantitative method of evaluating for recognize people, based on thermograms. The main purpose of the research was to write a computer program for quantitative method of evaluating for recognize people, based on thermograms. The application makes a selection of discrimination properties from thermal image - the analyze is provided for I level statistical parameters obtained from luminance histogram and II level statistical parameters obtained from: cooccurrence matrix parameterised by offset (4 directions and 3 neighborhoods), luminance matrix (for mask $3 \times 35 \times 5$ ), Run Length Matrix, wavelet transform. The best discrimination parameters are selected by Fisher-Tippett. The artificial neural network (ANN) is used to determine the number of people from thermograms.
\end{abstract}

\section{Introduction}

The images that are obtained from the use of thermal camera are valuable source of information about observed objects because it gives possibilities to visualise temperature field at the whole observing surface. It matters particularly during observation at places with limited visibility, so everywhere where visual observation is impossible. In the case of observing people with the use of thermal camera the effect of thermal emission of radiation from human is used and the specifically shaped human's figure. It's quite obvious that during thermal observation of random scenes there can be more objects at thermal image and their registered surface's temperature can be the same or similar to the temperature registered at the surface of human. Temperature that is recorded at human's surface depends on outside conditions, clothes or physiological state. Considering changes of position that change significantly the shape of registered objects the method of evaluating number of persons at registered thermal image should use algorithm of segmentation which means dividing image to a pixel region. The homogeneous criterion of chosen regions is the level of luminance at recorded image. The levels of luminance correspond with the registered temperatures.

The main purpose of this research is to draw up the algorithm to select the discriminative properties. This algorithm will allow to evaluate number of persons at registered thermogram.

\section{The algorithm of images segmentations}

The algorithm of segmentation thermal images that is used for quantitative method of evaluating for recognising people based on thermograms consists of described below levels. Firstly, the level of loading thermal images to further analysis. Registered thermal images are shown in grey scale. Figure 1 presents exemplary image that was taken to further analysis. 


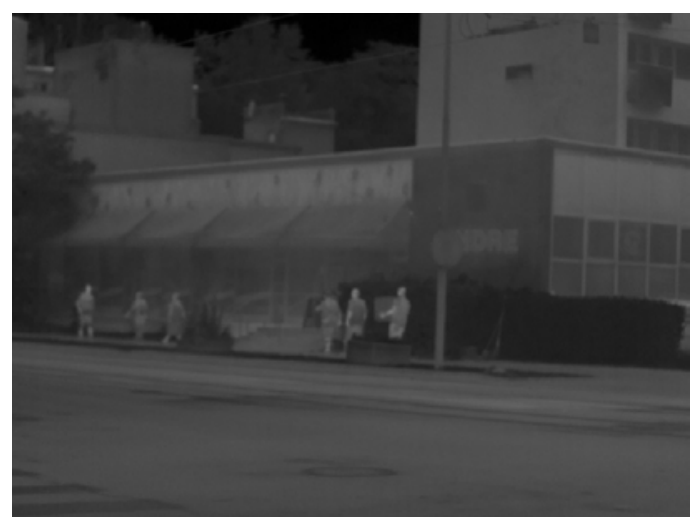

Fig. 1. Example of thermogram to future analysis

Then (the level of opening and closing areas by reconstruction) morphological processes of reconstructed image are done preceded by erosion of analysed monochromatic image. This process corresponds with minimal filter functioning $[1,2]$. The image of so called marker is transformed basing on second image called mask. As a starting point of reconstruction the local's maximums of the image are selected. The dilatation of marker's images comes to the level that marker's outlines cover mask's image. "Expansion" of top values of marker's image causes characteristic blurred object's outlines. Exemplary analysed thermal image after level of opening and closing by reconstruction is presented in the figure $2 \mathrm{a}$ and $2 \mathrm{~b}$.

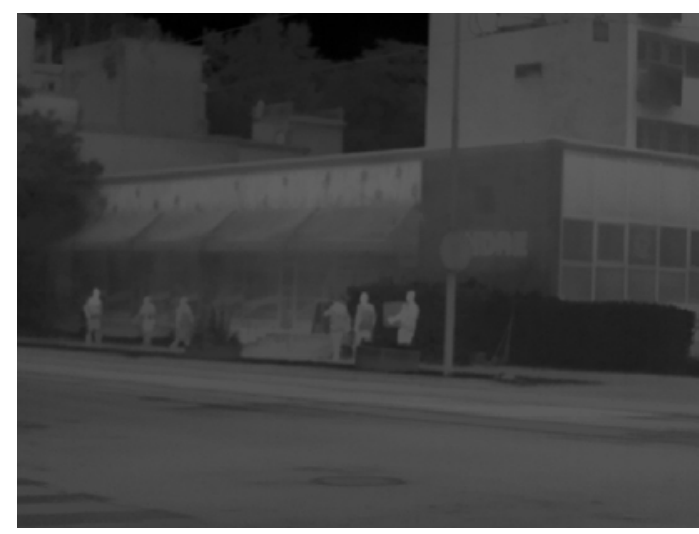

(A)

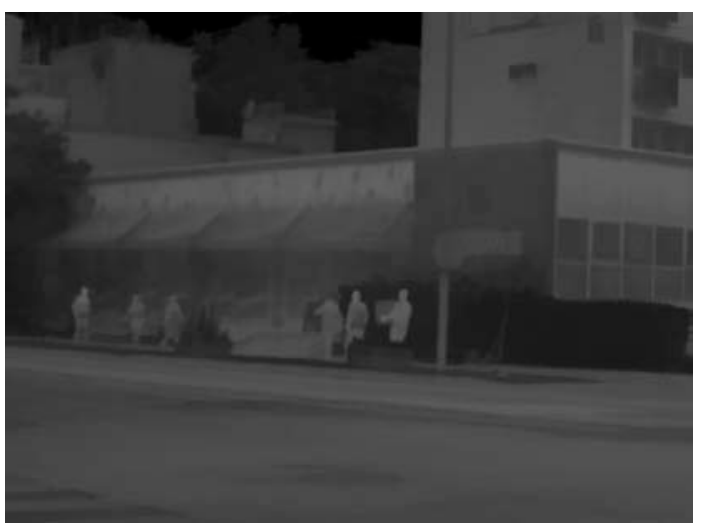

(B)

Fig. 2. Example of thermogram after $(A)$ opening and $(B)$ closing by reconstruction

Morphological processes of opening and closing areas by reconstruction are used to separate and average temperature of objects coming out from the background. Then regional maximums that their surroundings belong to the certain range of pixel variety are selected. This process is repeated over ten times for different value ranges and obtained images are averaged. The result of this process is monochromatic image that is presented (for described case) in the figure 3. 


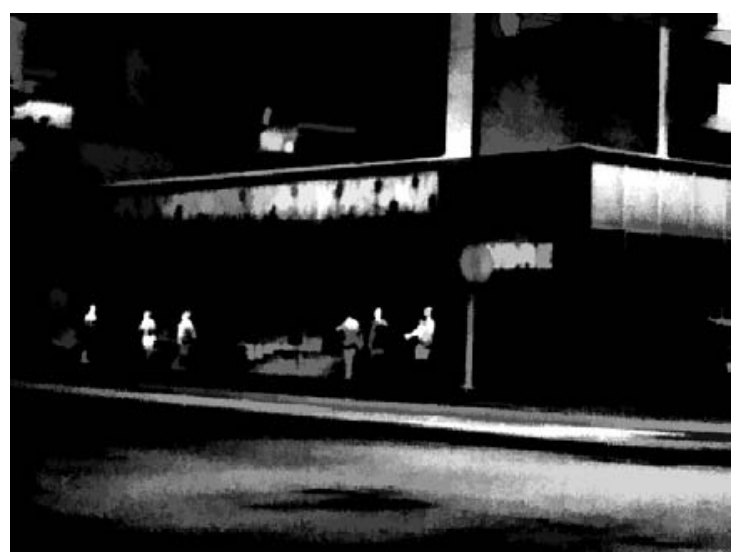

Fig. 3. Example of thermogram after selection of regional maxims

Further, the sequence morphological processes were carried at the monochromatic image (closing, opening, dilatation) in order to bring out human's figure in the image, what is presented in figure 4.

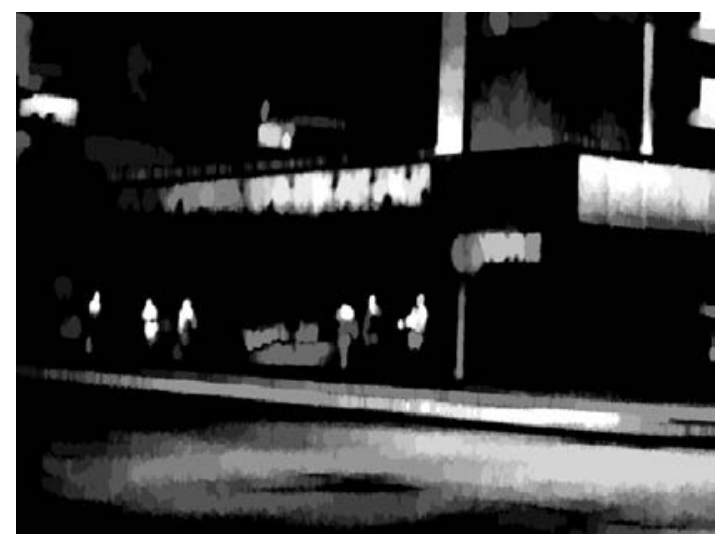

Fig. 4. Monochromatic image after morphological processes

Then the binary threshold is defined by Otsu method [3]. (look at figure 5). After binary process the morphological process of opening was carried in order to part areas connected by the small number of pixels. The dilatation process with vertical structural elements was also used to bring out vertical human's figure (look at figure 6). Then the region that doesn't show selected morphological properties is rejected. (look at figure 7). In order to observe the whole human's figure the interest region that are situated close to each other are joined basing on such properties as: size, centre and weight (look at figure 8). 


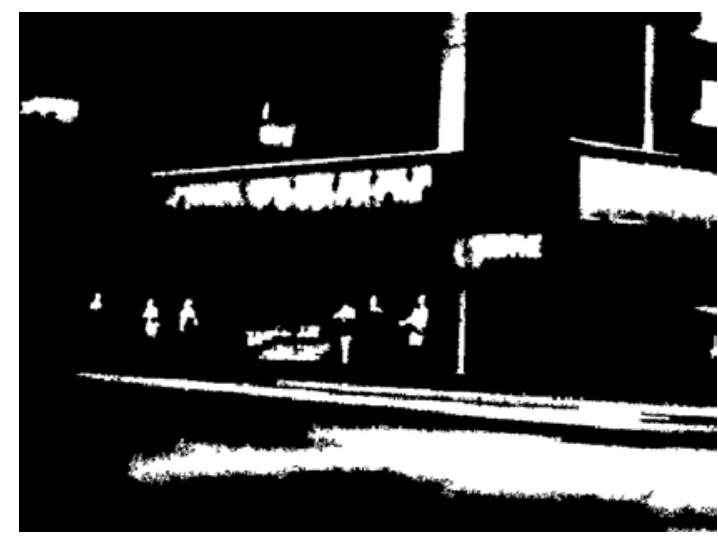

Fig. 5. Binary threshold - Otsu method

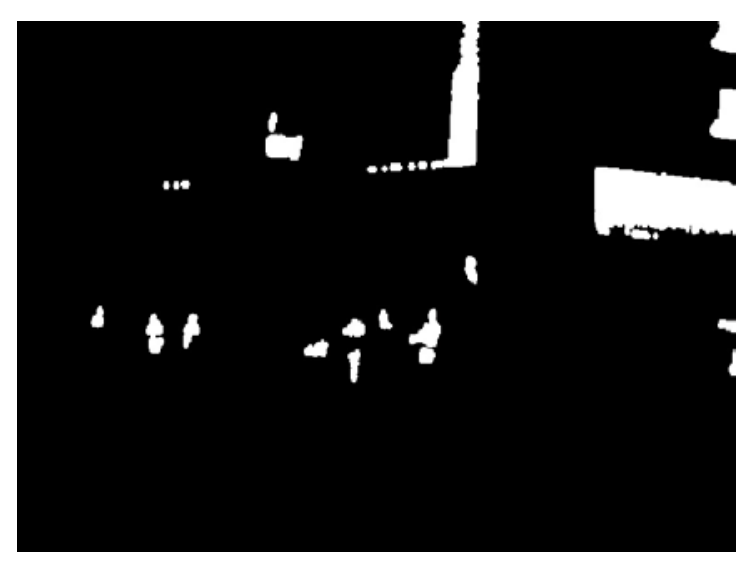

Fig. 7. Picture after rejected regions

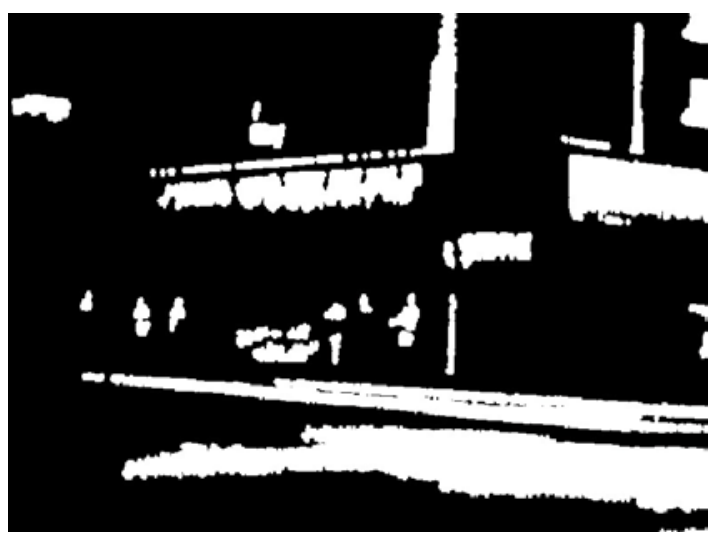

Fig. 6. The dilatation process

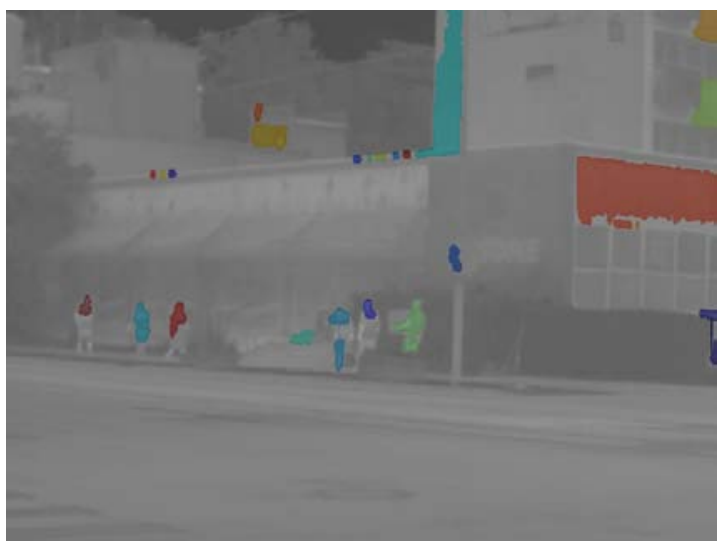

Fig. 8. Picture after joined regions

Then the extraction of rectangular areas that contains left regions of interest and parameters' calculation selected regions of interest is done [4]. To determine number of people that are in the registered thermograms the three-layered neural network is used. First and second layer -6 neurones. Third layer 1 neurone [5].

\section{The Thermosearch Programme}

Based on described algorithm the original software was written. This software is used to recognise and count people from thermal images. It contains two significant modules. First module (that runs from the MATLAB level) has following possibilities:

- $\quad$ generating new data base with selected parameters defined by neural network,

testing thermovision images.

Second module runs independently as a "exe" file. The module is designed for testing thermal images. The test is based on data base created in the first module. Both modules operate on images saved as MAT. Written software runs at two stages. First stage discovers regional maxims and then segments image creating the regions of interests at the same time. Obtained areas are tested by the neural network to define membership of that area to one of two classes. At the next stage, areas are joined to select human figure and then to repeat test by neural network. The result of this programme is an image with marked areas that the possibility of belonging to the human class is the highest. 


\section{Control tests}

The control tests with the use of described above algorithm were accomplished with the use of thermal camera ThermaCam P620 ( pictures resolution 640x480). Registered images created three following bases which, then, were used to test thermal images:

- $\quad$ night condition (surrounding's temperature about $15^{\circ} \mathrm{C} ; 43$ thermograms),

- $\quad$ day condition (surrounding's temperature about $20^{\circ} \mathrm{C} ; 43$ thermograms),

- $\quad$ day conditions (surrounding's temperature about $20^{\circ} \mathrm{C} ; 63$ thermograms).

In the registered thermograms there were elements of urban infrastructure ( residential buildings). There were also trees and cars. Then the selected thermal images were tested in accordance with the schemes presented in figures 9 and 10.

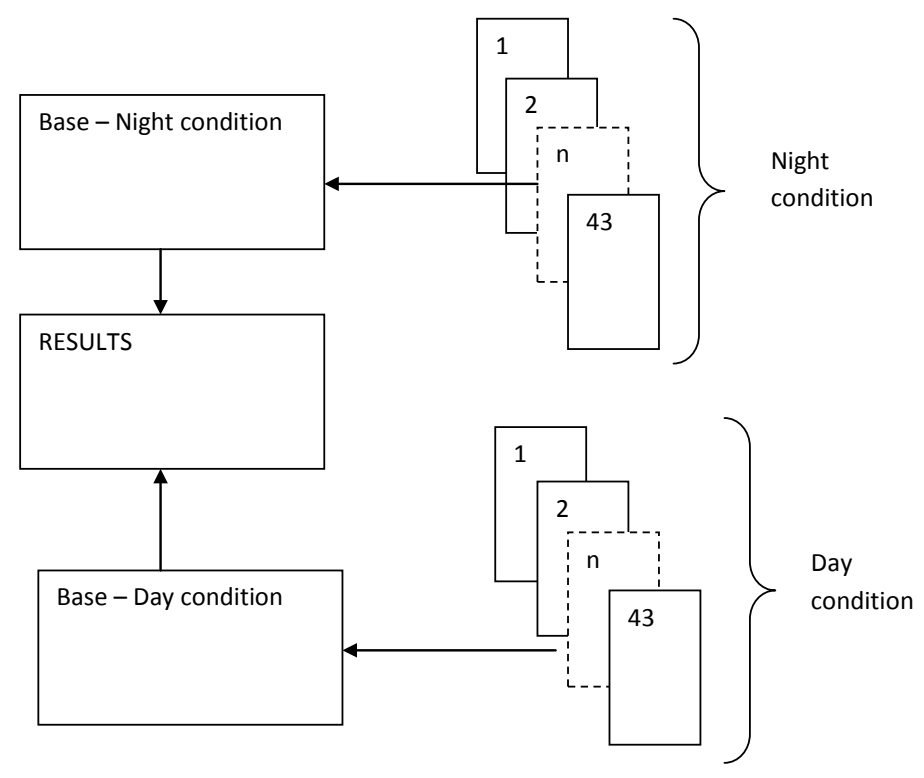

Fig. 9. Testing of thermal images - night and day condition

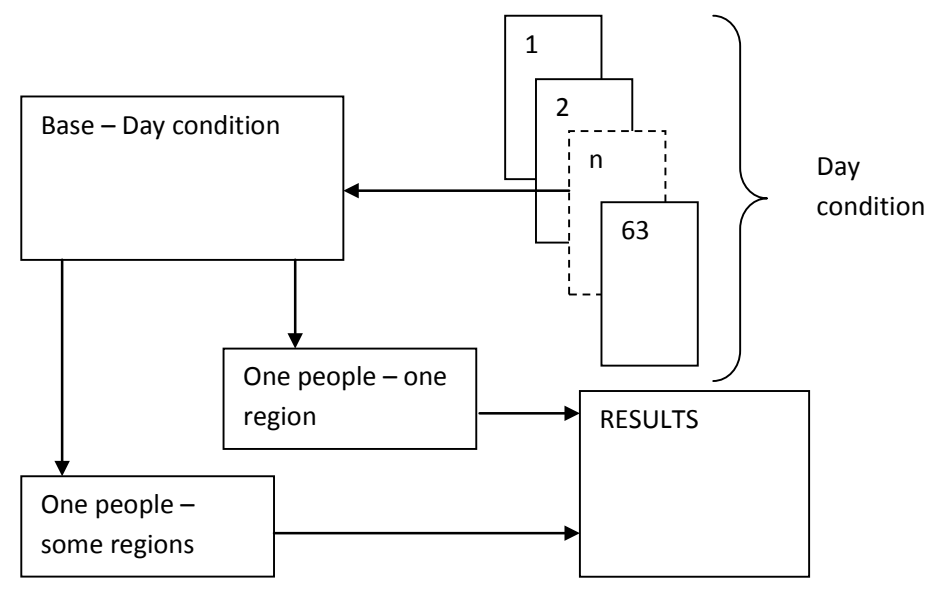

Fig. 10. Testing of thermal images - different regions classification 
The results of control tests with the use of schemes above are presented in the table 1 and drawings 11 and 12 .

Table 1. Results of control tests

\begin{tabular}{|c|c|c|}
\hline Specification & People quantity & $\%$ \\
\hline \multicolumn{3}{|c|}{ Night condition } \\
\hline $\begin{array}{l}\text { Total quantity of people on } 43 \\
\text { thermograms - night condition }\end{array}$ & 105 & \multirow{2}{*}{95,2} \\
\hline $\begin{array}{l}\text { Quantity of recognised people - night } \\
\text { condition }\end{array}$ & 100 & \\
\hline \multicolumn{3}{|c|}{ Day condition } \\
\hline $\begin{array}{l}\text { Total quantity of people on } 43 \\
\text { thermograms - day condition }\end{array}$ & 133 & \multirow{2}{*}{81,2} \\
\hline $\begin{array}{l}\text { Quantity of recognised people - day } \\
\text { condition }\end{array}$ & 108 & \\
\hline \multicolumn{3}{|c|}{ Day condition } \\
\hline $\begin{array}{l}\text { Total quantity of people on } 63 \\
\text { thermograms - day condition }\end{array}$ & 402 & - \\
\hline $\begin{array}{l}\text { Quantity of recognised people - one } \\
\text { region for one people }\end{array}$ & 376 & 93,3 \\
\hline $\begin{array}{l}\text { Quantity of recognised people - some } \\
\text { regions for one people }\end{array}$ & 351 & 87,1 \\
\hline
\end{tabular}

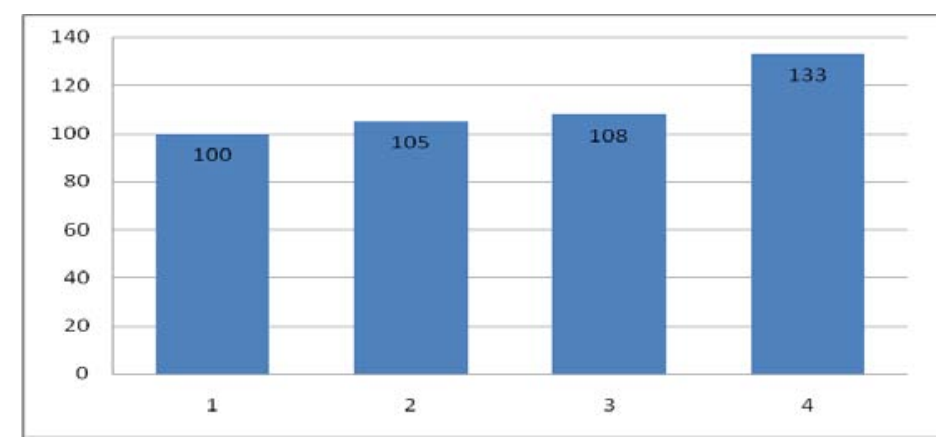

Fig. 11. People quantity: (1) - Recognised in night condition; (2) - Total quantity in night condition; (1) Recognised in day condition; (2) - Total quantity in day condition

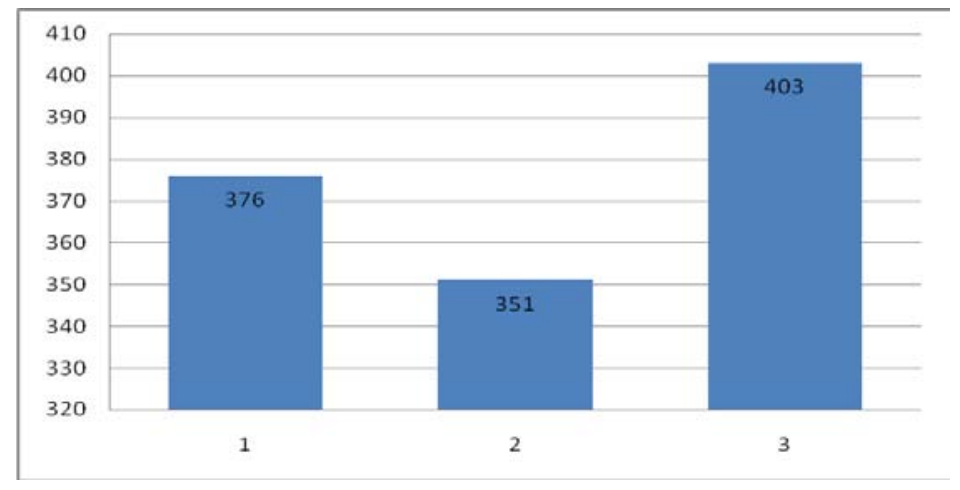

Fig. 12. People quantity: (1) - Recognised using one region for one people; (2) - Recognised using some regions for one people; (3) - Total quantity 
The thermogram with marks showing the people on analysed pictures is presented on figure 13.

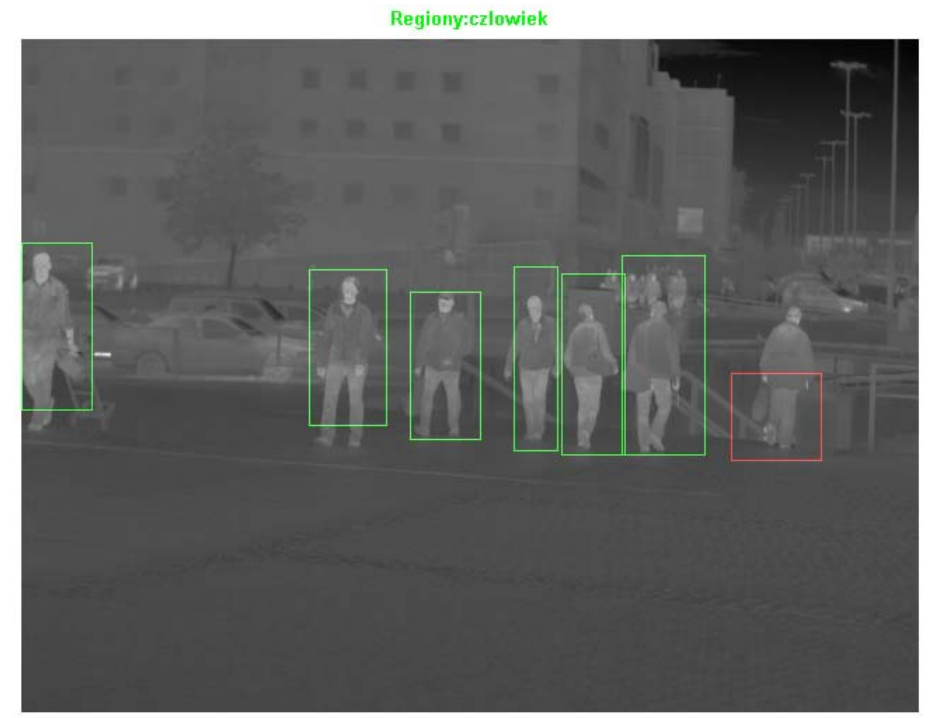

Regiony:obiekt

Fig. 10. The thermogram with marks showing the people on analysed pictures

Presented results of control test shows that better results are obtained while analysing thermograms that were done at night conditions. Algorithm detected $81,2 \%$ persons from the whole number of persons (the sum of persons from every 43 registered thermograms) at day conditions and 95,2\% persons at night conditions. In case of analyses with different region classification better result was obtained for classification - one region one people $(93,3 \%)$.

\section{REFERENCES}

[1] Image Processing Toolboc User's Guide, Version 5, The Mathworks

[2] Vincent, L., "Morphological Grayscale Reconstruction in Image Analysis: Applications and Efficient Algorithms," IEEE Transactions on Image Processing, Vol. 2, No. 2, April, 1993, pp. 176-201.

[3] Otsu, N., "A Threshold Selection Method from Gray-Level Histograms," IEEE Transactions on Systems, Man, and Cybernetics, Vol. 9, No. 1, 1979, pp. 62-66

[4] Tadeusiewicz, R., "Sieci neuronowe", Akademicka Oficyna Wydawnicza, Warszawa 1993, ISBN 83-85769-03-X

[5] MaZda User's Manual, Technical University of Lodz, http://www.eletel.p.lodz.pl/mazda/

[6] Więcek B., Peczynski-Drews C., Wysocki M., Jakubowska T., Danych R., Zwolenik S. "Advanced Methods of Thermal Image Processing for Medical and Biological Applications", Thermography and Lasers in Medcine Edited by Bogusław Więcek, Lodz 2003, ISBN 83-89003-82-1

\section{ACKNOWLEDGMENT}

This work was supported by the Central Institute for Labour Protection - National Research Institute (Grants N R18 $005104)$ 